\title{
Abcès médullaire
}

\section{Spinal Abscess}

\author{
A. Sarfati · C. Gast $\cdot$ P. Ray
}

Reçu le 13 mars 2015 ; accepté le 20 juillet 2015

(C) SFMU et Lavoisier SAS 2015
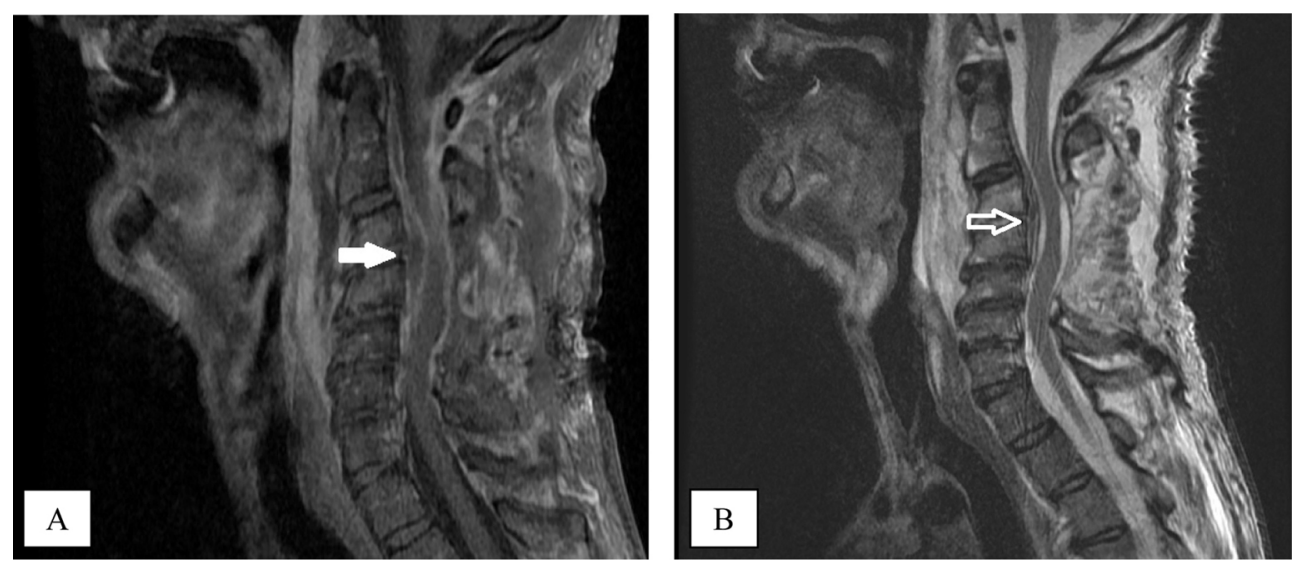

Fig. 1 A : IRM cervicale séquence T1 saturation du signal de la graisse (FAT SAT) montrant un hyposignal en regard de C3, C4, C5 (flèche pleine). B : IRM séquence T2 FLAIR (Fluid Attenuated Inversion Recovery) sans injection de gadolinium, montrant un hyposignal au même niveau (flèche vide)

Un patient de 53 ans se présente aux urgences pour fièvre à $38,9^{\circ} \mathrm{C}$, un syndrome méningé, un déficit sensitivomoteur des membres supérieur et inférieur gauches, et un globe vésical apparu le jour même. Les symptômes ont débuté dans un contexte de cervicalgies d'horaire inflammatoire évoluant depuis cinq jours, traitées jusqu'alors par anti-inflammatoires non stéroïdiens et antalgiques. L'unique antécédent du patient est une toxicomanie intraveineuse sevrée, actuellement substituée par méthadone. Le test rapide pour le virus de l'immunodéficience humaine revient négatif. La ponction lombaire (PL) retrouve 240 hématies, 75 éléments nucléés, dont $70 \%$ de lymphocytes, $12 \%$ de polynucléaires neutrophiles, et une protéinorachie à 2,64 g/L. Le scanner crânien non injecté réalisé avant la PL ne retrouve pas d'anomalie, et est complété secondairement par la réalisation d'un scanner crânien

\section{A. Sarfati $\cdot$ C. Gast $(\bowtie) \cdot$ P. Ray}

Service d'accueil des urgences, hôpital Tenon, 4 rue de la Chine, F-75020 Paris, France

e-mail : claire.gast@tnn.aphp.fr injecté descendant sur les premières vertèbres cervicales, qui met en évidence une masse comprimant la moelle en regard des vertèbres $\mathrm{C} 3, \mathrm{C} 4, \mathrm{C} 5$. L'IRM médullaire évoque un abcès intracanalaire extramédullaire (Fig. 1) [1]. Une antibiothérapie intraveineuse probabiliste par amoxicilline et gentamicine est instaurée. Cet abcès est drainé chirurgicalement [2] et les prélèvements bactériologiques retrouvent un Staphylococcus aureus, motivant une adaptation de l'antibiothérapie par péfloxacine pendant sept semaines. Les hémocultures réalisées aux urgences reviennent positives à la $18^{\mathrm{e}}$ heure au même germe. L'échographie transthoracique n'a pas retrouvé d'endocardite. Le patient sort de l'hôpital au bout de six semaines avec une bonne évolution neurologique.

\section{Références}

1. Reihsaus E, Waldbaur H, Seeling W (2000). Spinal epidural abscess: a meta-analysis of 915 patients. Neurosurg Rev 23:175-204

2. Smith GA, Kochar AS, Manjila S (2014) Holospinal epidural abscess of the spinal axis: two illustrative cases with review of treatment strategies and surgical techniques. Neurosurg Focus 37: E11 